\title{
Responsabilidade, ética e solidariedade ambiental
}

\author{
Ethical, responsibility and environmental solidarity
}

\author{
Fernanda Malmann', Roberto Naime ${ }^{2}$
}

\begin{abstract}
'Doutoranda do Programa de pós-graduação em Qualidade Ambiental, Universidade Feevale, Novo Hamburgo, Brasil
\end{abstract} ${ }^{2}$ Professor do Programa de pós-graduação em Qualidade Ambiental, Universidade Feevale, Novo Hamburgo, Brasil

\section{Resumo}

Este artigo faz uma abordagem do estado atual do tema de responsabilidade, ética e solidariedade ambiental, a luz da teoria do risco de Ulrich Beck e buscando verificar as formas de contribuição que a positivação dos direitos pode contribuir com o estado atual do tema. Existe um enfoque na determinação da necessidade de preservação das características ambientais para o usufruto das gerações futuras em condições de manutenção de qualidade ambiental que possa ser determinante na qualidade de vida das futuras gerações, com abordagem a partir do direito intergeracional no tema ambiental, emoldurado pelas características impostas pela sociedade de risco.

Palavras-chave: ética, responsabilidade e solidariedade

\begin{abstract}
This article is an approach to the current state of the theme of responsibility, ethics and environmental solidarity, the light of the theory of risk of Ulrich Beck and seeking ways to verify the contribution that positivization rights can contribute to the current state of the subject. There is a focus on determining the need for preservation of environmental features for the enjoyment of future generations in terms of maintenance of environmental quality which may be decisive in the quality of life of future generations, to approach from the right in intergenerational environmental theme, framed by characteristics imposed by the risk society.
\end{abstract}

Keywords: etics, responsability and solidaritity 


\section{INTRODUÇÃO}

O tema responsabilidade há muito é debatido nos mais variados sentidos e aspectos, por vezes com vinculação à filosofia, religião, ética, à moral, às sociedades complexas, aos direitos: humanos, civil, penal, etc., e agora, mais modernamente, também, na seara ambiental.

A fim de ressaltar ainda mais a importância do seu estudo, nos permitimos utilizar a observação de Klaus Günther de que "Em cada época há certas palavras às quais se vincula mais intimamente o espírito objetivo de uma sociedade. Isso se torna perceptível não apenas pelo uso freqüente dessas palavras na comunicação cotidiana, mas especialmente porque seu uso não provoca qualquer objeção, nem ao menos a pergunta sobre quem ou o que é referido. Atualmente, o conceito de 'responsabilidade' parece desempenhar esse papel."1

E, em busca de uma aproximação mais efetiva da responsabilidade com o direito, mas, sem adentrarmos diretamente na dogmática jurídica, passamos rapidamente pela filosofia onde nos apoiamos sobre os ensinamentos de Castanheira Neves, que, para responder à radical pergunta de que "é ou não é o homem responsável?", leciona que "só o 'pensamento novo' pode ser o caminho.

"Embora saibamos das múltiplas direções que se pode dar à responsabilidade no mundo do direito, precisamos delimitar a abordagem, o que fazemos para o campo da responsabilidade ambiental e as gerações futuras, passando primeiramente, pela situação problema, seguindo pela tutela jurídica do ambiente, pela própria responsabilidade e por sua evolução.

\section{ESTADO DA ARTE DO TEMA}

Um dos graves problemas que se verifica quotidianamente em nossa sociedade é a falta de identificação e assunção da responsabilidade por parte do indivíduo, que está cada vez mais inserido em uma sociedade global, industrializada, em nítida expansão científica e tecnológica, por parte do indivíduo que vive e convive em uma sociedade do perigo, em uma verdadeira sociedade de risco, como muito bem denominou Ulrich Beck. ${ }^{2}$

Partindo com a análise das questões problemáticas e características da sociedade de risco e fortalecendo o discurso das relações entre Direito, Economia, Sociedade e sua evolução, os autores Beck e Giddens, ${ }^{3}$ avaliando a sociedade industrial, destacaram que a ciência e a tecnologia eram as chaves para a prosperidade material. E, diante da transição de uma primeira modernidade para a segunda modernidade, esta mesma ciência e tecnologia tornaram-se a base dos problemas que originaram os chamados novos riscos. Para $\mathrm{Beck}^{4}$, a ciência uniu-se à tecnologia e tudo transformou, o mundo se vê entre perigos e riscos, a noção de controle de risco dá lugar a múltiplas formas de riscos e atinge a população indiscriminadamente no momento em que tornam-se incalculáveis os perigos e riscos sociais.

Direcionando para um conceito ambiental, $\mathrm{Beck}^{5}$ esclarece que o desenvolvimento tecnológico, refletido até agora, vem demonstrar um esgotamento de recursos naturais diante do excesso de poluição, geração de resíduos, passivos ambientais e inadequadas práticas de consumo, tornando insustentável este modelo de progresso contemporâneo.

Uma linguagem científica das questões do Direito do Ambiente exige tradução específica por parte de seus operadores, que se vêem, cada dia mais, obrigados a entender e produzir respostas a esse meio. Neste contexto, Ost descreve:

"A questão da tradução da linguagem científica da ecologia para a linguagem normativa dos juristas é aqui colocada. Para traçar o limite do permitido e do interdito, instituir responsabilidades, identificar os interessados, determinar campos de aplicação de regras no tempo e no espaço, o direito tem o costume de se servir de definições com contornos nítidos, critérios estáveis, fronteiras intangíveis.

\footnotetext{
1 GÜNTHER, Klaus. Responsabilização na sociedade civil. In Teoria da Responsabilidade no Estado Democrático de Direito. Tradução do alemão: Flávia Portella Püschel, editora Saraiva, 2008, p. 1, SP, Brasil.

2 BECK, Ulrich. Risk society: towers a new modernity. London: Sage, 1992.

3 BECK, Ulrich. A reivindicação da Política: rumo a uma teoria da modernização reflexiva. In: BECK, Ulrich; GIDDENS, Anthony; LASH, Scott. Modernização reflexiva: política, tradição e estética na ordem social moderna. São Paulo: UNESP, 1997.

4 BECK, Ulrich. A reivindicação da Política: rumo a uma teoria da modernização reflexiva. In: BECK, Ulrich; GIDDENS, Anthony; LASH, Scott. Modernização reflexiva: política, tradição e estética na ordem social moderna. São Paulo: UNESP, 1997.

5 BECK, Ulrich. La Sociedad de Riesgo. Hacia uma nueva modernidad. Barcelona: Paidós, 2006.
} 
A ecologia reclama conceitos englobantes e condições evolutivas; o direito responde com critérios fixos e categorias que segmentam o real. A ecologia fala em termos de ecossistemas e de biosfera, o direito responde em termos de limites e de fronteiras; um desenvolve o tempo longo, por vezes extremamente longo, dos seus ciclos naturais, o outro impõe o ritmo curto das previsões humanas. E eis o dilema: ou o direito do ambiente é obra dos juristas e não compreende, de forma útil, um dado decididamente complexo e variável; ou a norma é redigida pelo especialista e o jurista nega este filho bastardo... recheado de números e de definições incertas, acompanhado de listas intermináveis e constantemente revistas...E no entanto, juristas e científicos, de igual modo mobilizados pela urgência ecológica, são condenados a entenderem-se." (OST,1997, p.111)

O Direito é a ciência que busca e regula as relações sociais e um dever-ser entre indivíduos e Estado e Estado e cidadãos e, apesar de termos uma ordem jurídica única, dividimos as questões em direito público e direito privado. No entanto, esse direito que estamos discutindo, descrito e protegido constitucionalmente, o direito ao meio ambiente 'ecologicamente equilibrado', é direito difuso, garantido e merecido por todos os cidadãos indiscriminadamente.

\section{TUTELA JURÍDICA DO AMBIENTE}

O direito humano ao meio ambiente se dá a partir de reivindicações sociais por proteção dos recursos naturais como elemento essencial à sobrevivência da população. É um direito de caráter principiológico, que reflete efeitos sobre todo o ordenamento jurídico, orientando a interpretação e a aplicação das normas jurídicas.

A produção massificada e incontrolada de experimentos e aplicações de inovações tecnológicas propicia situações com reflexos não mais preconceituosos, mas generalizados (que atingem a todos indiscriminadamente) de direitos violados. São direitos econômicos, sociais e culturais, políticos e civis, como: direito a posse de terra; direito de ir e vir para os isolados; direito a saúde, trabalho e alimentação para grupos atingidos por contaminação e direitos de moradores de áreas de risco.

Diante do compromisso social do operador do Direito para a formação de uma ciência jurídica digna desta modernidade e pós-modernidade, a crise ecológica parece conferir certa transição de paradigmas, como descreve Ney de Barros Bello Filho: "Esta busca, ampla e plural que é, passa também por uma perspectiva emancipatória e não regulatória do Direito. Passa por uma redefinição do mundo jurídico que regula nosso relacionamento com o ambiente, com a casa, com o ecos. A busca passa por encontrar na norma ética uma dimensão solidária para o agir humano. Passa por definir a relação homem-ambiente a partir de outras bases, que não as da globalização neoliberal e do utilitarismo. Vivemos uma era de transição. Uma transição de paradigma, e por isto este caminho para uma segurança solidária e emancipatória, onde o homem não seja prisioneiro e não esteja ameaçado por suas próprias conquistas, passa pela conceituação de novos objetivos e passa pela criação de um novo paradigma, dentro do qual serão construídos novos direitos." 6

Um dos objetivos do Direito Ambiental é permitir um desenvolvimento sustentável, em que haja comprometimento com a dimensão temporal futura, ligando direitos e obrigações entre gerações passadas, presentes e futuras. E nisso podemos verificar a importância de haver abrandamento e antecipações referentes às avaliações do reconhecimento dos danos ambientais por instrumentos processuais vigentes. E quando não houver formas de bases ao Direito Ambiental por casos anteriores, o Direito deve criá-las.

O sistema jurídico, quando tratamos de responsabilidade ambiental, manifesta-se de forma vaga, diante da gravidade apresentada pela sociedade de risco quando falamos de proteção do meio ambiente. Acreditamos que "[...] apenas com o reconhecimento dos riscos da atualidade, o que pressupõe que sejam eles trazidos a público, o Direito Ambiental poderá ser alicerçado sobre novas bases que viabilizarão a efetiva utilização de seus instrumentos como forma de salvaguardar o meio ambiente ecologicamente equilibrado para as gerações presentes e futuras."

6 BELLO FILHO, Ney de Barros. Teoria do direito e ecologia: apontamentos para um direito ambiental no século XXI. In: FERREIRA, Heline Sivini; LEITE, Jose Rubens Morato. Estado do direito do ambiente: tendências, aspectos constitucionais e diagnósticos. Rio de Janeiro: Forense, 2004, p. 73.

7 FERREIRA, Helini Sivini. A sociedade de risco e o principio da precaução no direito ambiental brasileiro. Florianópolis. Dissertação do mestrado em direito. UFSC. 2003, p. 31. 
Embora o ordenamento jurídico-ambiental de alguns países possua instrumentos que não se limitam ao controle da produção e da proliferação de riscos, ressalta-se a necessidade de afastar o Direito Ambiental da racionalidade da irresponsabilidade organizada e desvinculá-lo da intenção do exercício de uma função meramente simbólica.

O desenvolvimento global descontrolado e uma necessidade de proteção efetiva do meio ambiente determinam o maior desafio das sociedades contemporâneas. Mais prudência ambiental e gestão de riscos adequada são as principais ocupações do Direito Ambiental. Mesmo com extrema capacitação técnica e científica, o ser humano já se torna impotente diante deste desenvolvimento insustentável que nos lançou a uma crise ecológica global em que o mundo atingiu os limites mais críticos da sua história.

Todo esse avanço das técnicas de produção são referenciais que provocaram profundas transformações não apenas na forma de organização das relações econômicas e sociais, mas, sobretudo no modo como seriam, a partir desse momento, definidas e legitimadas as relações de poder.

Em decorrência direta dessa evolução tecno-científica e de sua utilização imediata pelo sistema econômico, desde meados do século XX as instituições sociais da sociedade industrial enfrentam, sem precedentes históricos, a possibilidade de destruição das condições de vida no planeta, em virtude das decisões que são ou que possam ser tomadas. ${ }^{8}$

A tutela do meio ambiente é uma das grandes preocupações de todo cenário mundial. O desenvolvimento sustentável deve abranger critérios sociais, jurídicos, econômicos e também políticas públicas eficientes para que os seus reflexos sejam positivos na vida em sociedade, e o desenvolvimento econômico deve estar amparado aos liames de um Estado Democrático de Direito, dentro das perspectivas que norteiam a dignidade da pessoa humana.

Ainda assim, como nos ensina José Joaquim Gomes Canotilho "Como quer que seja, parece-nos que o tema do direito fundamental ao ambiente ainda não está esgotado. Tão pouco se vislumbra uma opinião dominante sobre a articulação das dimensões objectivas e das dimensões subjectivas do ambiente. Vale a pena, por isso, voltar às positivações jurídico-constitucionais do direito ao ambiente para tentar compreender a natureza e âmbito desse direito." ${ }^{\prime}$

$\mathrm{O}$ 'legislador constitucional', independente de caracterizar o meio ambiente como direito e da natureza deste direito, inquestionavelmente, preocupava-se também com obrigar o Estado e seus cidadãos a adotar medidas de prevenção e de proteção ao ambiente, sendo, normalmente, influenciado pela Conferência de Estocolmo de 1972 sobre o ambiente.

Ainda por José Joaquim Gomes Canotilho, "o problema está em saber que tipo de direito fundamental se pretende positivar na qualidade de direito fundamental ao ambiente". Devendo salientar que um significativo número de textos constitucionais evitaram a caracterização do ambiente como direito subjetivo. "Dir-se-á que, de certo modo, algumas constituições se preocuparam mais com o direito do ambiente do que com o direito ao ambiente." 10

$\mathrm{Na}$ mesma linha de raciocínio nos ensinam José Rubens Morato Leite e Patryck de Araújo Ayala que "Com o objetivo de construção de modelo de atividade de intervenção racional no texto constitucional, dirigido à realização e concretização de seu complexo normativo e principiológico, é conveniente enfatizar, desde o início, o papel de destaque que exerce hoje, no constitucionalismo ocidental contemporâneo, a imprescindível necessidade do desenvolvimento de uma Teoria da Interpretação Constitucional prévia e axiologicamente orientada pelo princípio democrático, que implica apresentar a hermenêutica da Constituição, antes do problema da realização e concretização da essencialidade da dupla dimensão dos direitos fundamentais da pessoa humana como problema de acesso adequado à Constituição."11

A Constituição da República Federativa do Brasil, de 1988, no Título VIII - Da Ordem Social - tem o Capítulo VI - Do Meio Ambiente - que no seu artigo 225, aborda exclusivamente sobre o direito

8 BECK, Ulrich. La Sociedad de Riesgo. Hacia uma nueva modernidad. Barcelona: Paidós, 2006, p. 83.

9 CANOTILHO, José Joaquim Gomes. O direito ao ambiente como direito subjectivo. Estudos sobre direitos fundamentais.

$2^{\text {a }}$ edição, Coimbra Editora, 2008, p. 178-179.

10 CANOTILHO, José Joaquim Gomes, idem, p. 179.

11 LEITE, José Rubens Morato e AYALA, Patryck de Araújo. Direito ambiental na sociedade de risco, 2ª edição, ed. Forense, Rio de Janeiro, 2004, p. 148-149. 
$\mathrm{ao}^{12}$ ambiente e direito do ${ }^{13}$ ambiente.

Dessa forma, denota-se claramente que a grande preocupação do 'legislador constituinte' atual é de afirmar e firmar cada vez mais o ambiente em patamar de importância tal que tenha sempre o direito ao ambiente e o direito do ambiente como um direito fundamental do cidadão (como indivíduo) e especialmente de toda a coletividade; mas também de um dever de preservação, prevenção, proteção e de responsabilidade e conseqüente responsabilização (civil, administrativa, política e criminal) de cada um de nós (e da sociedade) e também do Estado, olhando não apenas para a vida presente, como, com igual preocupação, para a vida das gerações futuras.

\section{EVOLUÇÃO DA RESPONSABILIDADE E SITUAÇÃO ATUAL}

Quando falamos de responsabilidade em matéria ambiental, estamos nos referindo diretamente aos princípios da Prevenção e da Precaução, fundamentais para o papel de evitar a ocorrência de danos ambientais e sua reparação depois de já ocorrido os danos.

Podemos dizer que, atualmente, podem ser observadas duas espécies de riscos: de um lado, os riscos concretos, característicos de uma formatação social de natureza industrial, e de outro, os riscos invisíveis ou abstratos, inerentes à Sociedade de Risco (ou pós-industrial). ${ }^{14}$

A partir da formação da Sociedade Industrial, os danos ambientais são, freqüentemente, produtos de várias causas concorrentes e sucessivas, não tendo como característica uma causalidade simples e sim muito complexa, fazendo da incerteza científica, um dos maiores obstáculos à imputação da responsabilidade.

Neste sentido, que José Afonso da Silva descreve: "Nem sempre é fácil determinar ou identificar o responsável. Sendo apenas um foco emissor, a identificação é simples. Se houver multiplicidade de focos, já é mais difícil, mas é precisamente por isso que se justifica a regra da atenuação do relevo do nexo causal, bastando que a atividade do agente seja potencialmente degradante para sua implicação

12 Constituição Brasileira

Art. 225, caput - Todos têm direito ao meio ambiente ecologicamente equilibrado, bem de uso comum do povo e essencial à sadia qualidade de vida, impondo-se ao Poder Público e à coletividade o dever de defendê-lo e preservá-lo para as presentes e futuras gerações.

13 Constituição Brasileira

Art. 225. (..)

$\S 1^{\circ}$ - Para assegurar a efetividade desse direito, incumbe ao Poder Público:

I - preservar e restaurar os processos ecológicos essenciais e prover o manejo ecológico das espécies e ecossistemas;

II - preservar a diversidade e a integridade do patrimônio genético do País e fiscalizar as entidades dedicadas à pesquisa e manipulação de material genético;

III - definir, em todas as unidades da Federação, espaços territoriais e seus componentes a serem especialmente protegidos, sendo a alteração e a supressão permitidas somente através de lei, vedada qualquer utilização que comprometa a integridade dos atributos que justifiquem sua proteção;

IV - exigir, na forma da lei, para instalação de obra ou atividade potencialmente causadora de significativa degradação do meio ambiente, estudo prévio de impacto ambiental, a que se dará publicidade;

$\mathrm{V}$ - controlar a produção, a comercialização e o emprego de técnicas, métodos e substâncias que comportem risco para a vida, a qualidade de vida e o meio ambiente;

VI - promover a educação ambiental em todos os níveis de ensino e a conscientização pública para a preservação do meio ambiente;

VII - proteger a fauna e a flora, vedadas, na forma da lei, as práticas que coloquem em risco sua função ecológica, provoquem a extinção de espécies ou submetam os animais a crueldade.

$\S 2^{\circ}$ - Aquele que explorar recursos minerais fica obrigado a recuperar o meio ambiente degradado, de acordo com solução técnica exigida pelo órgão público competente, na forma da lei.

$\S 3^{\circ}$ - As condutas e atividades consideradas lesivas ao meio ambiente sujeitarão os infratores, pessoas físicas ou jurídicas, a sanções penais e administrativas, independentemente da obrigação de reparar os danos causados.

$\S 4^{\circ}$ - A Floresta Amazônica brasileira, a Mata Atlântica, a Serra do Mar, o Pantanal Mato-Grossense e a Zona Costeira são patrimônio nacional, e sua utilização far-se-á, na forma da lei, dentro de condições que assegurem a preservação do meio ambiente, inclusive quanto ao uso dos recursos naturais.

$\S 5^{\circ}$ - São indisponíveis as terras devolutas ou arrecadadas pelos Estados, por ações discriminatórias, necessárias à proteção dos ecossistemas naturais.

$\S 6^{\circ}$ - As usinas que operem com reator nuclear deverão ter sua localização definida em lei federal, sem o que não poderão ser instaladas.

14 BECK, Ulrich. Risk Society: towards a new modernity. London: Sage, 1992.; LEITE, José Rubens Morato; AYALA, Patryck de

Araújo. "Transdisciplinariedade e a proteção jurídico-ambiental em Sociedades de Risco: direito, ciência e participação." In: Direito

Ambiental Contemporâneo. José Rubens Morato Leite e Ney de Barros Bello Filho (orgs). Barueri: Manole, 2004. p. 103. 
nas malhas da responsabilidade" 15

A realidade dos riscos contemporâneos vem mostrar ao Direito, o desafio de propor alternativas para problemas que não podem mais ser analisados, apenas restritivamente, em âmbito de ações locais e atuais. Necessitamos atualmente de uma resposta jurisdicional, quando tratamos de causas ambientais, através de uma análise mais aprofundada de causas e conseqüências, atuais e futuras.

A questão da responsabilização em matéria ambiental tem como principal objetivo a Prevenção e possui como função, além da Prevenção e da Precaução do dano, também a internalização dos custos ambientais; o encorajamento das empresas para investimentos e desenvolvimento para aumentar o conhecimento e melhorar a tecnologia; e o fomento de atitudes mais responsáveis por parte dos poluidores.

Apesar de a preocupação ambiental ter crescido muito nos últimos anos, o Direito Ambiental ainda é um ilustre desconhecido para muitos e boa parte da população, considera a legislação ambiental um obstáculo ao desenvolvimento econômico. Sobre o assunto, discorre, Tessler: "Como não se pode obstar o desenvolvimento, é necessário que a sociedade - e, sobretudo o direito - instrumentalizem-se com o fim de administrar este problema. Para o empresariado, o risco passou a ser mais um dos fatores a ser incorporado na atividade econômica da empresa; o peso da internalização do risco precisa ser contabilizado no processo produtivo. Ao legislador, surge a função de delimitar o grau de tolerabilidade do risco a partir da definição de ilícitos. Ao judiciário, compete a função de prestar a adequada tutela contra o risco." 16

Segue a autora, sobre o papel do Estado:

"A função de fixar o grau de necessidade e suportabilidade do risco compete à norma. Cabe ao legislador a ponderação acerca dos benefícios trazidos pela atividade perigosa e a gravidade do risco dela decorrente. Se após este sopesamento concluir que a atividade, a despeito do perigo, é conveniente para a sociedade, deve permiti-la. Ao contrário, se a atividade produzir risco intolerável ao ordenamento, deve ser vedada pela norma.

Ainda sobre o princípio da Precaução quanto à degradação do meio ambiente, este passou a ser aceito, tanto no âmbito internacional como no nacional, especialmente nas últimas três décadas. Inovou-se o tratamento jurídico relativo a estas questões, evitando antagonismos de leis, decretos e portarias. Implementar o princípio da precaução, não quer dizer, imobilizar as atividades humanas ou o impedimento a tudo, este princípio surge para visar à durabilidade da sadia qualidade de vida das gerações futuras e à continuidade de uma vida natural farta, existente em nosso planeta.

Em virtude do excesso de possibilidades que existe na Sociedade Contemporânea pode ser entendido que os sistemas sociais (dentre eles o Direito) operam em contextos de "bounded rationality" (racionalidade limitada). A formação de uma Teoria do Risco no Direito coloca a comunicação jurídica não apenas num fechamento normativista, tomando-se decisões com base em experiências e decisões passadas condensadas nas estruturas sistêmicas (jurisprudência e regras), mas, sobretudo acresce ao Direito a possibilidade lançar seus olhares ao futuro. ${ }^{17}$

Não se pode esperar a concretização do dano para que sejam tomadas decisões, principalmente porque danos ambientais em sua maioria são irreversíveis, e esse é o maior motivo de aplicação pelo Direito, dos princípios da prevenção e da precaução. Mesmo no RS já existem julgados que falam de probabilidade relevante, para a condenação de empresa por dano ambiental, baseados em laudos técnicos, como colacionamos:

Ementa: Ação de Indenização. Poluição Ambiental. Agentes Poluentes. Perícia. Nexo Causal. Tendo a perícia comprovado o procedimento nocivo da ré, poluindo o meio ambiente com a emissão de partículas diretamente e sem tratamento ao meio ambiente externo à empresa, de forma não compatível com as legislações que regem a matéria e que, por isso, advieram danos aos autores, assente a obrigação de indenizar. Quadro alérgico congênito. Não obstante a patologia da autora se justifique por quadro alérgico congênito, acentuado pelo hábito de fumar, concluindo o laudo pericial que ela estava exposta por longo lapso de tempo aos diversos fatores agressivos decorrentes da atividade poluidora da empresa, que contribuíram efetivamente para o

15 SILVA, José Afonso da. Direito ambiental Constitucional. 2ª ed. 2ª tiragem, São Paulo: Malheiros,1998.

16 TESSLER, Luciane Gonçalves. Tutelas Jurisdicionais do Meio Ambiente. Dissertação de Mestrado em Direito. Curitiba: Universidade Federal do Paraná, 2003, p. 149.

17 CARVALHO, Délton Winter de. Novas tecnologias e direito ambiental. Ob.cit. p.103 
desencadeamento, ou agravamento da patologia diagnosticada, presentes os pressupostos da responsabilidade civil e decorrente obrigação de indenizar. Sentença mantida. Apelo desprovido. ${ }^{18}$

Nesta passagem da sociedade industrial para a sociedade de risco caracterizada pelos riscos globais, invisíveis e imprevisíveis, que verificamos diversas situações como aquecimento global, biotecnologia, chuvas ácidas, transgênicos, etc, riscos transindividuais e transfronteiriços, não existindo mais a comprovação de uma verdade científica. Assim, sempre que falarmos em sociedade de risco, somos obrigados a falar de futuro, de um risco abstrato, de necessidade de decidir antes do resultado. Passamos de uma verificação da teoria do risco concreto para criação da teoria do risco abstrato. Ulrich Beck $^{19}$ chama esta nova realidade histórica de uma "modernização reflexiva", é a sociedade lidando com os riscos que ela própria produziu. Não há mais a certeza científica, previsível, calculável, não há mais a distribuição de riquezas e sim de riscos, potencializou-se a indústria, com produções novas e uma tecnologia imaterial.

Como também descreve o sociólogo Ulrich Beck, a característica da sociedade de Risco é que vivemos com distribuição de riquezas. Estamos em uma era imaterial e não de concretude, e esta é a grande diferença da verdade científica e da atual incerteza científica. Beck, ainda lembra de chamar os riscos abstratos de riscos de nova face, invisíveis, quer dizer, não temos a possibilidade de visualizá-los, caso contrário não ocorreria o caso de Chernobyl, por exemplo, que representou o primeiro envenenamento gradual, que não é perceptível ao sentido humano, onde populações estavam sendo contaminadas sem sentir.

\section{NOVA POSTURA E RESPONSABILIDADE ATUAL PARA AS GERAÇÕES FUTURAS}

Passamos por uma crise ética da individualização das responsabilidades e da assunção da responsabilidade por parte dos indivíduos e ainda pelos perigos iminentes que esses indivíduos passam por viverem em uma sociedade de risco que, por sua vez, em nada se preocupa com as pessoas que formarão as denominadas futuras gerações.

Em razão das características próprias da sociedade pós-industrial e seus inúmeros riscos ambientais, observamos uma verdadeira ratificação da crise da responsabilização na área ambiental, onde a regra conseqüencial é primariamente a reparação e a indenização.

Conforme ensina José de Faria Costa, "o modelo clássico de responsabilidade (...) arranca fundamentalmente de duas idéias força: causalidade e individualidade e é constituído por três elementos. Estes, como ninguém desconhece, são o sujeito responsável, a instância moral ou institucional perante a qual se responde, e a natureza do nexo de responsabilidade - o chamado domínio da responsabilidade - que liga aqueles dois elementos. Para se ser responsável necessário é, dentro destes pressupostos, que se estabeleça um nexo entre o agir ou o omitir humanos que se estruturaram, necessariamente, em uma vontade livre, e o resultado desvalioso ou valioso que se queria evitar ou prosseguir. (...) $\mathrm{O}$ problema é que hoje - como já se deixou dito em forma mais do que insinuada - é impossível continuar a defender o mesmo modelo de responsabilidade. Não só a individualidade se estilhaçou em plúrimas individualidades com dignidades iguais, como por outro lado, os resultados se não cristalizam em efeitos imediatamente visíveis no futuro presente. Só são visíveis no futuro longínquo, absolutamente separado por gerações e gerações." 20

Exige-se da responsabilidade que sejam dadas respostas a diversas frentes, como reparar pelo dano causado, repartir perdas, distribuir riscos, punir o lesante, prevenir comportamentos ilícitos, controlar a atividade da produção e, sendo assim, maior e mais exigente reflexão do que a determinada pelo alargamento da responsabilidade pelo risco, devendo ser vista a responsabilidade como verdadeiramente pluralista e não mais no sentido unitário, trazendo, assim, um modelo de responsabilidade social.

18 Ap. Civ., TJRS, 9ª̣ Câmara Cível, rel. juíza Ana Lúcia Carvalho Pinto Vieira, j. 27.11.2002.

19 BECK, Ulrich. . La Sociedad del Riesgo Global. Madrid: Siglo Veintiuno de España Editores, 2002.

20 COSTA, José de Faria. Linhas de direito penal e de filosofia: alguns cruzamentos reflexivos. Coimbra Editora, 2005 p. 35-36. 


\section{CONSIDERAÇÕES FINAIS - PARA ALÉM DA RESPONSABILIDADE, A SOLIDARIEDADE}

A partir de uma revolução industrial, as relações sociais apresentaram a necessidade de uma reorientação envolvendo o Direito, a Sociedade e a Economia, tudo devido á exagerada potencialização da técnica e da ciência. Desta forma, o Direito não pode mais resolver suas questões baseado em conceitos tradicionais de responsabilidade.

A sociedade pós-moderna ou de risco, tem como principal característica a generalização da incerteza o do risco das atividades. Isso vem apresentar grande desafio para o Direito, diante da dificuldade em regular essas situações novas, fazendo com que essa ciência avance nas discussões quanto a princípios e processos de tomada de decisão.

O problema desta incerteza é que, o progresso científico e tecnológico, a muito, trabalha na medida em que novas tragédias surgem. Precisamos adotar mecanismos que evitem a degradação do meio e não apenas sua recuperação quando já ocorrido à situação danosa.

A multiplicidade de fatores e situações; a invisibilidade de riscos; a temporalidade entre atividade e resultado e as incertezas relacionadas ao problema, são os aspectos mais dificultosos ao reconhecimento da responsabilização por riscos ambientais. É importante para qualquer tomada de decisão, tanto administrativa quanto judicial, analisar a estrutura dos riscos ambientais desde sua geração até seus potenciais efeitos e a exposição da saúde e meio ambiente aos riscos existentes no passado e no presente e os possíveis efeitos futuros.

Embora abordados diversos aspectos quanto à responsabilidade, aproveitamos ainda, um dos ensinamentos de Castanheira Neves, quando afirma que "para além da responsabilidade pode considerar-se a solidariedade. Solidariedade para com os carecidos e as vítimas sociais, e também do destino, a que a sociedade e nós todos nela sejamos chamados. Só que - ponto essencial - distinguindo bem responsabilidade (jurídica) e solidariedade (humana). E nesse caso não terá sequer de convocar-se uma responsabilidade que seja compreendida a exorcizar o absurdo da dor humana na assunção de uma culpa originária que nos solidarize, simplesmente aí, humanidade, responsabilidade e solidariedade identificam-se."21

Por fim, a importante aplicação do princípio da precaução como forma de participação pelo Direito, no gerenciamento dos riscos ambientais, não só concretos, mas também abstratos. Devemos trabalhar com instrumentos preventivos e até mesmo proibitivos, se assim se fizer necessário, para a defesa deste bem constitucionalmente protegido que é o meio ambiente.

\section{REFERÊNCIAS}

ANTUNES, Paulo de Bessa. Curso de direito ambiental: doutrina, legislação e jurisprudência. Rio de Janeiro: Renovar, 2002, p. 130.

BARROS-PLATIAU, Ana Flavia; VARELLA, Marcelo Dias. O princípio de precaução e sua aplicação comparada nos regimes da diversidade biológica e de mudanças climáticas. Revista de Direitos Difusos, São Paulo, v. 12 , abr. 2002.

BECK, Ulrich. La Sociedad de Riesgo. Hacia uma nueva modernidad. Barcelona: Paidós, 2006.

La Sociedad del Riesgo Global. Madrid: Siglo Veintiuno de España Editores, 2002.

A reivindicação da Política: rumo a uma teoria da modernização reflexiva. In: BECK, Ulrich; GID-

DENS, Anthony; LASH, Scott. Modernização reflexiva: política, tradição e estética na ordem social moderna. São Paulo: UNESP, 1997.

21 NEVES, A. Castanheira. Pessoa, direito e responsabilidade. Revista Portuguesa de Ciência Criminal, no 6, 1996, p. 43 
BELLO FILHO, Ney de Barros. Teoria do direito e ecologia: apontamentos para um direito ambiental no século XXI. In: FERREIRA, Heline Sivini; LEITE, Jose Rubens Morato. Estado do direito do ambiente: tendências, aspectos constitucionais e diagnósticos. Rio de Janeiro: Forense, 2004.

CANOTILHO, José Joaquim Gomes. O direito ao ambiente como direito subjectivo. Estudos sobre direitos fundamentais. $2^{a}$ edição, Coimbra Editora, 2008, p. 178-179.

. Estado constitucional ecológico e democracia sustentada. In: GRAU, Eros Roberto; CUNHA, Sérgio Sérvulo da (Coord.). Estudos de direito constitucional. São Paulo: Malheiros, 2003, p. 101-110.

CANOTILHO, José Joaquim Gomes; LEITE, Jose Rubens Morato. Direito Constitucional Ambiental Brasileiro. São Paulo: Saraiva, 2007, p. 142.

COSTA, José de Faria. Linhas de direito penal e de filosofia: alguns cruzamentos reflexivos. Coimbra Editora, 2005 , p. 34.

CUSTÓDIO, Helita Barreira. Responsabilidade civil por danos ao meio ambiente. Campinas: Millennium, 2006, p. 102.

DE GIORGI, Raffaele. Direito, Democracia e Risco: vínculos com o futuro. Porto Alegre: Sergio Antonio Fabris, 1998.

DERANI, Cristiane. Direito Ambiental Econômico. São Paulo: Max Limonad, 1997.

FERREIRA, Helini Sivini. A sociedade de risco e o principio da precaução no direito ambiental brasileiro. Florianópolis. Dissertação do mestrado em direito. UFSC. 2003.

GARDNER, Daniel. Risco: a ciência e a política do medo. Rio de janeiro: Odisséia, 2009.

GIDDENS, Anthony. As conseqüências da modernidade. São Paulo: UNESP, 1991.

GIDDENS, Anthony; BECK, Ulrich; LASH, Scott. Modernização Reflexiva: política, tradição e estética na ordem social moderna. São Paulo: Unesp, 1997.

GÜNTHER, Klaus. Responsabilização na sociedade civil. In Teoria da Responsabilidade no Estado Democrático de Direito. Tradução do alemão: Flávia Portella Püschel, editora Saraiva, 2008, p. 1, SP, Brasil.

HAMMERSCHMIDT, Denise. O Risco na Sociedade Contemporânea e o Princípio da Precaução no Direito Ambiental. Revista de Direito Ambiental, vol. 8, n. 31, p. 136-156, jul./set. 2003.

LEITE, José Rubens Morato e AYALA, Patryck de Araújo. Direito ambiental na sociedade de risco, $2^{\mathrm{a}}$ edição, ed. Forense, Rio de Janeiro, 2004, p. 148-149.

MILARÉ, Edis. Direito do Ambiente. 7. ed. rev. atual. e ampl. São Paulo: Revista dos Tribunais, 2011, p. 443.

MONTEIRO, Jorge F. Sinde. Estudos sobre a responsabilidade civil, ed. Almedina, 1983, p. 7.

MONTEIRO, Jorge F. Sinde. Proteç̧ão dos interesses econômicos na responsabilidade civil por dano ambiental. In: A tutela jurídica do meio ambiente: presente e futuro. Boletim da Faculdade de Direito da universidade de Coimbra, Studia Jurídica, $n^{\circ} 81$, colloquia ${ }^{\circ} 13$, p. 150.

NEVES, A. Castanheira. Pessoa, direito e responsabilidade. Revista Portuguesa de Ciência Criminal, $n^{\circ} 6$, 1996, p. 32-38. 
OST, François. A natureza à margem da lei: a ecologia à prova do direito. Lisboa, Portugal: Instituto Piaget, 1997.

PORTO, Marcelo Firpo de Souza. Uma Ecologia Política dos Riscos: Princípios para integrarmos o local e o local na promoção da saúde e da justiça ambiental. Rio de Janeiro: Fiocruz, 2007.

PRIGOGINE, Ilya. O fim das certezas: tempo, caos e as leis da natureza. São Paulo: UNESP, 1996.

REXACH, Angel Menéndez. Protagonismo Del derecho administrativo em La prevención y tutela Del médio ambiente. In: A tutela jurídica do meio ambiente: presente e futuro. Boletim da Faculdade de Direito da universidade de Coimbra, Studia Jurídica, $n^{\circ} 81$, Colloquia ${ }^{\circ} 13$, p. 61. 